\title{
Comics Tattoos: normas e singularidade ${ }^{1}$ João Batista Freitas Cardoso
}

\section{Resumo}

0 presente texto visa caracterizar diferentes tipos de usos de Comics Tattoos e verificar seu potencial de significação. Para alcançar os objetivos, foram realizadas entrevista em profundidade e análise documental, com base na semiótica peirciana. As entrevistas e análises permitiram constatar que existem diferentes formas de uso dos personagens como tatuagens, que são definidas em razão da história que se deseja contar. Ao se apropriarem de imagens da indústria de comunicação e entretenimento, o tatuador e o sujeito tatuado estabelecem "acordos" entre as normas que orientam a apropriação e reprodução de imagens de personagens de histórias em quadrinhos e as convenções e os hábitos relacionados ao uso e prática de se tatuar.

\section{Palavras-Chave}

Personagem. Comics Tattoos. História em Quadrinhos. Semiótica Peirciana.

João Batista Freitas Cardoso | jbfcardoso@uol.com.br Doutor em Comunicação e Semiótica pela Pontifícia Universidade Católica de São Paulo - PUC-SP, Brasil. Pós-doutor em Comunicação pela Universidade de São Paulo - USP, Brasil. Professor do PPGCOM da Universidade Municipal de São Caetano do Sul - USCS, Brasil, e do Curso de Graduação em Publicidade e Propaganda da Universidade Presbiteriana Mackenzie, Brasil.

\section{Introdução}

0 presente texto, que aborda o movimento Comics Tattoo, parte de dois pressupostos básicos: primeiro, de modo geral, quem faz uma tatuagem pretende preservar na memória, ou comunicar, algo que considere importante; segundo, imagens de personagens de histórias em quadrinhos e desenhos animados são utilizadas de diferentes modos, fora das narrativas seriadas, para expressar ideias e sentimentos individuais e coletivos. Com base nessa crença, pretendese responder às seguintes perguntas: De que maneiras o portador de tatuagem de personagem faz uso desse tipo de signo para narrar suas próprias histórias? Qual é o potencial de significação dessas imagens?

Para compreender como o portador de tatuagem faz uso do personagem para narrar suas histórias, foram feitas entrevistas em profundidade com pessoas que possuem tatuagem de personagem. Essas entrevistas também visaram identificar traços comportamentais e discursos comuns entre os portadores desse tipo de tatuagem. E para 
analisar o potencial de significação das imagens, foi realizada análise semiótica com base na categorização sígnica de Charles S. Peirce.

Para as entrevistas, foram selecionadas apenas pessoas que possuem pelo menos $50 \%$ de suas tatuagens com figuras de personagens de histórias em quadrinhos ou desenhos animados. Esse percentual se deve ao fato de entendermos que essas pessoas atribuem uma importância especial a esse tipo de signo. Neste trabalho ${ }^{2}$, são apresentados dados coletados em duas entrevistas: uma com um comerciante brasileiro de 43 anos, casado, pai de dois filhos, que reside na cidade de Mauá, que chamaremos de Personagem A (PA) ${ }^{3}$; e um estudante português de 21 anos, solteiro, residente na cidade de São Paulo, que chamaremos de Personagem B (PB) ${ }^{4}$. As entrevistas em profundidade permitiram obter acesso aos modos pelos quais os entrevistados atribuem significados a esse tipo de signo e as relações que estabelecem com suas experiências de vida.

Essas entrevistas nos possibilitaram perceber que, ainda que os entrevistados compartilhem o mesmo interesse pelo tema, existem diferentes formas de uso dos personagens como tatuagens, e essas formas de uso são definidas em razão da história que se deseja contar. Em suma: cada personagem no corpo de PB narra um aspecto particular de seus pensamentos ou história; no corpo de PA, por sua vez, o sentido principal é gerado em função do conjunto de personagens. No primeiro, predomina a lógica da singularidade como modo de narrar momentos específicos de sua vida; no outro, a lógica da coletividade permite preservar parte da infância.

Na análise semiótica, a atenção se voltou ao interpretante imediato, o potencial que 0 signo tem para comunicar. Para isso, recorre-se às classificações sígnicas propostas na gramática especulativa, primeiro ramo da semiótica peirciana. Como o objeto, em si, não solicita a aplicação de todos os conceitos desenvolvidos por Peirce, não será detalhado o procedimento de acordo com cada categoria ou classe de signos.

Antes de comparar os discursos dos entrevistados com o potencial de significação das imagens, são revistas algumas ideias já desenvolvidas em outros trabalhos, que tratam: das formas de apropriação dos personagens fora do contexto

Auxílio: processo\#2014/21537-5, Fundação de Amparo à Pesquisa do Estado de São Paulo (FAPESP)

Esta fase compreende o período de 1\%02/2015 a 31/06/2016. 0 Período de Vigência da pesquisa é de 1\%/02/2015 a 31/01/2017.

Entrevista realizada em 16 de setembro de 2015. 
de suas histórias (CARDOSO; SANTOS, 2015); dos aspectos que caracterizam o personagem como um tipo de linguagem gráfica (ibid.); e dos modos como as tatuagens são utilizadas para narrar histórias de vida e construir identidades (CARDOSO, 2016).

\section{0 personagem como signo que transcende a narrativa}

Desde o final do século XIX, os personagens de histórias em quadrinhos já eram utilizados fora do contexto das narrativas seriadas para promover produtos, serviços ou ideias, como: jornais, livros, musicais, chocolates, cigarros, sapatos, relógios, tecidos, bebidas, cafés, pães, maçãs, pianos, entre outros (GORDON, 1998). 0 personagem Yellow Kid, criado por Richard Outcault em 1895, foi o primeiro a mostrar que esse tipo de imagem poderia ser utilizado para incrementar a venda de produtos. Tal prática comercial revelou que o personagem poderia "transcender as histórias em quadrinhos para se tornar um ícone cultural" (GORDON, 1998, p. 37-38, tradução nossa).

Os quadrinhos publicados nos jornais estadunidenses no início do século XX surgiam também como um fenômeno social que refletia a emergente cultura consumista da época. A difusão das imagens dos personagens, para Gordon, reflete uma urbanização da cultura estadunidense. Assim, os quadrinhos participaram diretamente na transformação da cultura urbana, a qual não era marcada apenas pelo aumento do consumo de bens e serviços, mas também pelo consumo de bens simbólicos.

Gordon ainda relata que nos primórdios das histórias em quadrinhos parques de diversão já eram construídos com temáticas baseadas nos personagens e, na primeira metade do século XX, personagens originários das tirinhas dominicais ou revistas de histórias em quadrinhos já se exibiam nas telas da televisão, cinema e nos palcos da Broadway. Na década de 1960, nos trabalhos de Roy Lichtenstein e Andy Warhol, eles chegaram às artes. "Personagens de tirinhas e revistas de histórias em quadrinhos haviam transpassado o meio de sua origem" (GORDON, 1998, p. 156, tradução nossa).

De acordo com Taliaferro e Odden, as primeiras tatuagens de personagens - chamada de comics tattoo no mercado de tatuagem - apareceram na metade do século XX: "Bugs Bunny, The Road Runner, Betty Boop, Mickey Mouse, Might Mouse, Maggie e Jiggs, Mutt e Jeff, e até mesmo Pink Panther" (2012, p. 6). Contudo, se comparada às outras temáticas (religiosas, orientais, ameríndias, etc.), a opção por fazer um comics tattoo ainda é muito pequena (OSÓRIO, 2006), o que indica tratar-se de um perfil restrito de consumidor.

Em outros trabalhos, temos levantado a hipótese de que o portador de tatuagens desse tipo é, em sua maioria, um aficionado por histórias em quadrinhos (CARDOSO, 2016). Alguém que acompanha as histórias de seus personagens 
favoritos em revistas, filmes, animações, games e coleciona objetos diversos que trazem a estampa do personagem. Com base em um texto de John Fiske ("The Cultural Economy of Fandom"), Pustz (1999) categoriza os fãs em dois tipos básicos: active producer; e users. Sem ser necessariamente excludente, o primeiro tipo reúne os fãs que geram novos textos, novos significados, e outro, que se contenta em falar sobre 0 assunto ou exibir em camisetas imagens de seus personagens favoritos. Essas categorias podem ser aplicadas tanto ao tatuador especialista em Comics Tattoo quanto ao portador de tatuagens de personagens.

$\mathrm{PB}$, que possui onze figuras de super-heróis tatuados em seu corpo, reforça essa hipótese ao declarar: "a decoração da minha casa é feita basicamente por super-heróis [...] e eu acho que eles estão presentes o tempo inteiro na minha vida". Além do interesse pessoal por esse segmento, PB é sócio em uma empresa que comercializa revistas em quadrinhos antigas pela internet: "Nós vamos aos sebos, vemos os quadrinhos que estão numa qualidade melhor, pegamos esses quadrinhos e revendemos na internet [...]. Nós estamos abrindo agora espaço para esse $e$-commerce através de publicações, informações sobre heróis". Assim como PB, PA, que possui mais de 120 tatuagens de personagens, coleciona diversos objetos relacionados ao tema e é proprietário de um estabelecimento comercial decorado com referências antigas da cultura midiática: fotos de filmes e seriados, capas de revistas e discos de vinil, brinquedos e imagens de personagens animados da televisão e de histórias em quadrinhos.

Assim como outros indivíduos tatuados, 0 portador de comics faz uso de um repertório para falar de si e sobre o que pensa do mundo. No entanto, por estarem presas às narrativas, as imagens das personagens, muitas vezes, contam suas próprias histórias.

\section{Tatuagem e Personagem como sistemas independentes}

No ambiente social, os signos são selecionados e organizados para gerar sentidos predeterminados. No caso das tatuagens, 0 portador, muitas vezes orientado pelo tatuador, seleciona as figuras, define 0 tratamento estético, escolhe o local do corpo, com vistas a mostrar, ou dizer, algo para alguém. Visa provocar nesse alguém uma reação qualquer. Logo, tanto a escolha das figuras quanto as formas de exibição têm uma finalidade comunicacional. Existem motivações diversas que fazem com que uma pessoa opte por tatuar uma determinada imagem: laços afetivos com outras pessoas, crenças religiosas, valores sociais e políticos, vínculos com agremiações esportivas, estética e moda, etc. As relações existentes entre os personagens das narrativas ficcionais seriadas e os portadores de comics revelam uma motivação particular. 
Para Fruh e Thomas (2012), a tatuagem pode ter um efeito de ancoragem, amarrando, por meio de narrativas, pontos entre 0 passado, presente e futuro na formação de uma resposta para a questão de quem eu sou. Entretanto, como lembra Lee (2012), as histórias e os eventos narrados por meio das tatuagens não são sempre verdadeiros. Assim como a identidade é uma espécie de narrativa em curso, uma construção de sentido formada ao longo do tempo, as histórias e os eventos narrados são concebidos por meio da memória e imaginário do portador. Nesse sentido, mais do que narrarem o passado, as tatuagens dizem "quem nós somos agora" (SMITH, 2012, p. 110). Ou, de outro modo, quem nós queremos parecer ser agora. Dessa forma, ao tentar delinear sua identidade e narrar sua história de vida, 0 indivíduo revela sua perspectiva sobre o mundo e sobre si mesmo (FALKENSTERN, 2012). E, ao tentar explicar ou justificar o sentido da figura tatuada, o indivíduo constrói, por meio de um conjunto de associações, suas próprias narrativas (PEREZ FONSECA, 2014). Essa construção de narrativas apresenta-se, então, em um equilíbrio instável entre algo que se pretende dizer sobre si e o modo como são lembrados os eventos ou fatos vividos. Por um lado, elas informam como a pessoa pretende ser vista, por outro, são construídas de maneira que não se tornem pura fantasia (FRUH; THOMAS, 2012).

Também é sabido que toda tatuagem, além de estar relacionada a traços particulares ou fases de uma vida, revela vínculos coletivos, pois "no tipo de tatuagem há a eleição de imagens que estão permeadas pela relação de afetividade e cumplicidade com os produtos culturais massificados pela mídia" (PAVAN, 2010, p. 209). Antes de assumirem um valor simbólico no corpo humano, grande parte das figuras já expressa comportamento ou valor, como no caso das imagens de personagens em quadrinhos.

A personalidade do personagem, os aspectos visíveis que compõem seu caráter individual, as qualidades que 0 diferenciam de outros personagens são o que realmente interessa a quem traz sua imagem no corpo. Tais características, que são análogas ao conjunto de aspectos psíquicos ou comportamentais humanos, são desenvolvidas nas narrativas. Nelas, o caráter individual do personagem é construído por meio dos discursos e das ações do protagonista, do antagonista e de personagens secundários. De modo geral, a repetição desses discursos nos diálogos, nos monólogos e nas ações serve para estruturar uma personalidade coerente e simplificada.

Como os discursos, ações e conflitos tendem a se repetir nas histórias em quadrinhos ou desenhos animados, é comum encontrar histórias que possuem estruturas narrativas que se repetem. Consequentemente, essas estruturas exigem do personagem uma regularidade de comportamento. Assim, não é apenas a estrutura narrativa que se repete, mas também certas frases e a apresentação visual do personagem. 
Para manter o controle sobre a padronização visual dos personagens, as grandes editoras, mainstream, utilizam modelos preestabelecidos (model sheets). Esses modelos servem como base para reprodução do personagem em outros suportes. São justamente essas poses, gestos, expressões e falas, já conhecidas pelo público, que tendem a definir a personalidade do personagem. Por isso, é natural que certos padrões de imagem apareçam nas estampas de camisetas, mochilas e outros tipos de produtos em maior quantidade.

Além das características visuais e da estrutura narrativa, outros tipos de signos são importantes no processo de construção da personalidade do personagem. As mídias audioverbovisuais (cinema, TV, games) agregam à personalidade do personagem elementos que não estão presentes na imagem impressa, como, por exemplo, o tom da voz ou movimento do corpo. Logo, é presumível que, ao ver uma figura estampada em um produto licenciado (camiseta, capa de caderno, etc.), ainda que o personagem não esteja no contexto de uma narrativa, traços comportamentais, que envolvem também a maneira de gesticular ou falar, estejam presentes de forma implícita.

\section{É justamente essa sobreposição de sentidos} que interessa, de maneira geral, à pesquisa: 0 potencial de significação da figura do personagem; o potencial de significação da imagem gravada no corpo humano; e os sentidos que o portador procura gerar quando explica as motivações que 0 levaram a tatuar determinado personagem.
Sob esse ponto de vista é que serve ao estudo a compreensão do interpretante imediato. Conforme elaborado por Peirce, o conceito de interpretante (imediato, dinâmico ou final) refere-se ao efeito que um signo causa, ou pode causar, em uma mente. É o potencial interpretativo do signo, ou seja, as possibilidades de significados que um determinado signo é capaz de provocar. Dizer que um signo tende a gerar determinados sentidos é prever que, ao ser percebido por um intérprete particular, ele tende a produzir efetivamente efeitos emocionais, energéticos e/ou lógicos, os quais estão no nível do interpretante dinâmico. Para fazer certas predições sobre os potenciais interpretativos de um signo, é preciso considerar o repertório do intérprete, construídos, nos termos de Peirce, em experiências colaterais. Considerando que nos processos comunicativos, na dimensão social, os signos são selecionados e organizados para se dirigir a um tipo específico de intérprete, surge uma nova pergunta: a quem essas "mensagens" são dirigidas?

Os locais de exposição das tatuagens definem 0 universo de observadores: umas se exibem de maneira explícita, no rosto ou nas mãos; outras não são expostas livremente, como nas costas, na nuca ou nas pernas; e existem aquelas que são extremamente reservadas, em partes íntimas do corpo. Ou seja, algumas tatuagens se exibem publicamente, outras para um número restrito e seleto de pessoas.

Assim como a parte do corpo, as figuras, que são utilizadas com diferentes propósitos, 
também tendem a se dirigir a grupos ou pessoas específicas: um salmo bíblico ou figura religiosa, o escudo ou trecho do hino de um time de futebol, os nomes dos pais ou o retrato do filho reforçam laços entre o portador e outras pessoas ou instituições; certas figuras, no ambiente carcerário, servem para identificar 0 tipo de crime praticado pelo detento; imagens de celebridades e letras de canções demonstram preferências culturais e vínculos com grupos específicos; alguns padrões de figuras ou tratamentos estéticos revelam uma tendência da moda e valores dos portadores. As mensagens, codificadas, implicam em um sistema de significação e sentido que resulta em um sistema de valores, os quais são aceitos e compreendidos por determinados grupos e não por outros.

Do mesmo modo que os sentidos podem ser gerados pela relação da tatuagem com a parte do corpo, ou pelo histórico ou convenções de uso da imagem, eles também podem ser produzidos pelo discurso do próprio portador. Pelas histórias que conta, pelas justificativas que dá, pelas associações que faz com sua história de vida ou crenças.

\section{Comics Tattoo: 0 que a imagem pode dizer e o que se diz sobre a imagem}

Para analisar o potencial de significação utilizando como método teórico aplicado à classificação dos signos proposta por Peirce, é preciso compreender que as qualidades dos signos se corporificam em signos particulares que são orientados por normas gerais. De outro modo, os modelos e as normas de reprodução dos personagens, assim como as técnicas e os hábitos relacionados à prática de se tatuar (individuais ou coletivos) funcionam como princípios-guias para a elaboração de cada tatuagem.

Por entender que há normas que orientam a apropriação e reprodução de imagens de personagens de histórias em quadrinhos, bem como convenções e hábitos relacionados ao uso e à prática de se tatuar, a análise se iniciará, no nível fundamental, pela identificação das generalidades que envolvem tais signos, domínio do legissigno. 0 estudo dos legissignos leva à observação de regras e convenções culturais, "que incluem os costumes e valores coletivos e todos os tipos de padrões estéticos, comportamentais, de expectativas sociais, etc." (SANTAELLA, 2002, p. 37).

\section{Normas e semelhança - do legissigno à iconicidade}

Fazendo um breve levantamento em sites especializados em tatuagens, observamos que existem padrões recorrentes de uso dos personagens das histórias em quadrinhos como tatuagens (CARDOSO; SANTOS, 2015): cenas ou gestos que se tornaram populares; detalhes ou símbolos conhecidos apenas pelos fãs; combinação das figuras dos personagens com frases de fontes literárias ou musicais; relações 
estabelecidas entre tatuagens em diferentes partes do corpo; capas de edições históricas de revistas; sequências de quadros com a história completa; figuras dos personagens alteradas que visam transgredir as normas de utilização das imagens; tatuagens de diferentes personagens de uma mesma história que funcionam como vínculo afetivo entre diferentes sujeitos. As opções por determinadas formas de uso dos personagens, seguindo modelos consolidados em outros sistemas (em camisetas ou capas de cadernos, por exemplo) ou criando novos sentidos na junção com códigos de outros sistemas (como literatura ou música), fazem com que o portador de tatuagem construa sua própria narrativa.

No corpo de PA predominam os modelos consolidados em outros sistemas, cenas de personagens em gestos que os tornaram populares nas revistas e na televisão e foram transpostos para produtos licenciados.

Além de copiar imagens já veiculadas nas mídias e em outros produtos, PA segue uma norma da área de licenciamento: manter os personagens de uma mesma história (protagonista, antagonista e secundários) em uma única unidade gráfica. Algumas de suas tatuagens são reproduções de imagens de divulgação da animação - como, por exemplo, as figuras dos personagens da série Carangos e Motocas (Figura 1) ou as figuras dos personagens da série Os Impossíveis (Figura 2). Para ele, a reprodução de imagens já veiculadas nas mídias e a reunião dos personagens em uma única unidade permitem rememorar com mais facilidade a estrutura narrativa.

Figura 1: Imagem dos personagens da série Carangos e Motocas: (A) como tatuagem nas costas de PA; (B) em ilustração de divulgação da série.
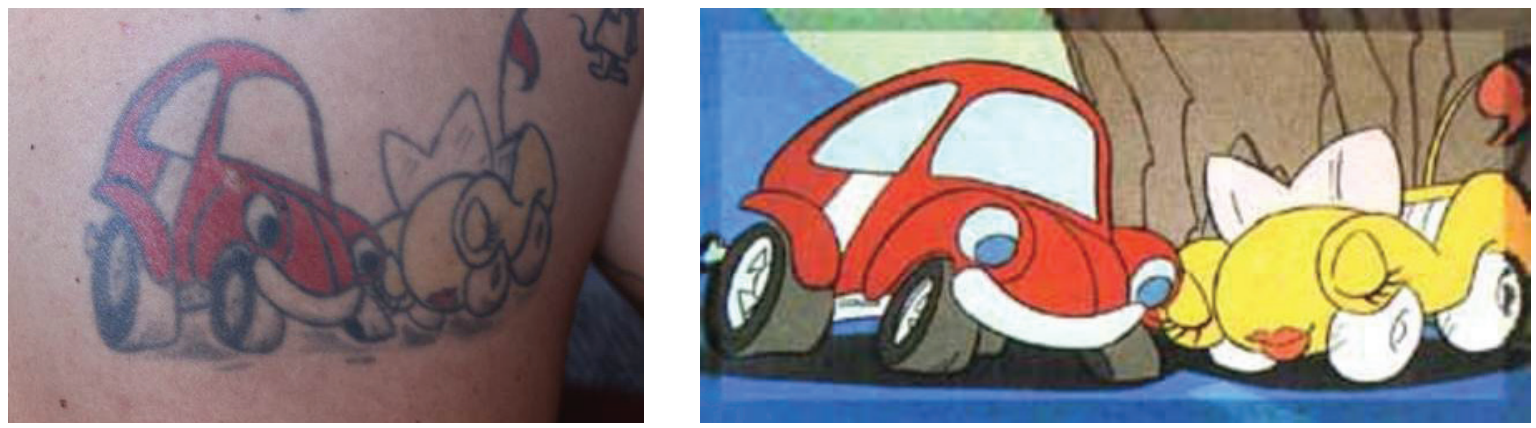

Fontes: (A) do autor, 2015; (B) site Hanna Barbera. 
Figura 2: Imagem dos personagens da série Os Impossíveis: (A) como tatuagem no tórax de PA; (B) em ilustração de divulgação da série.
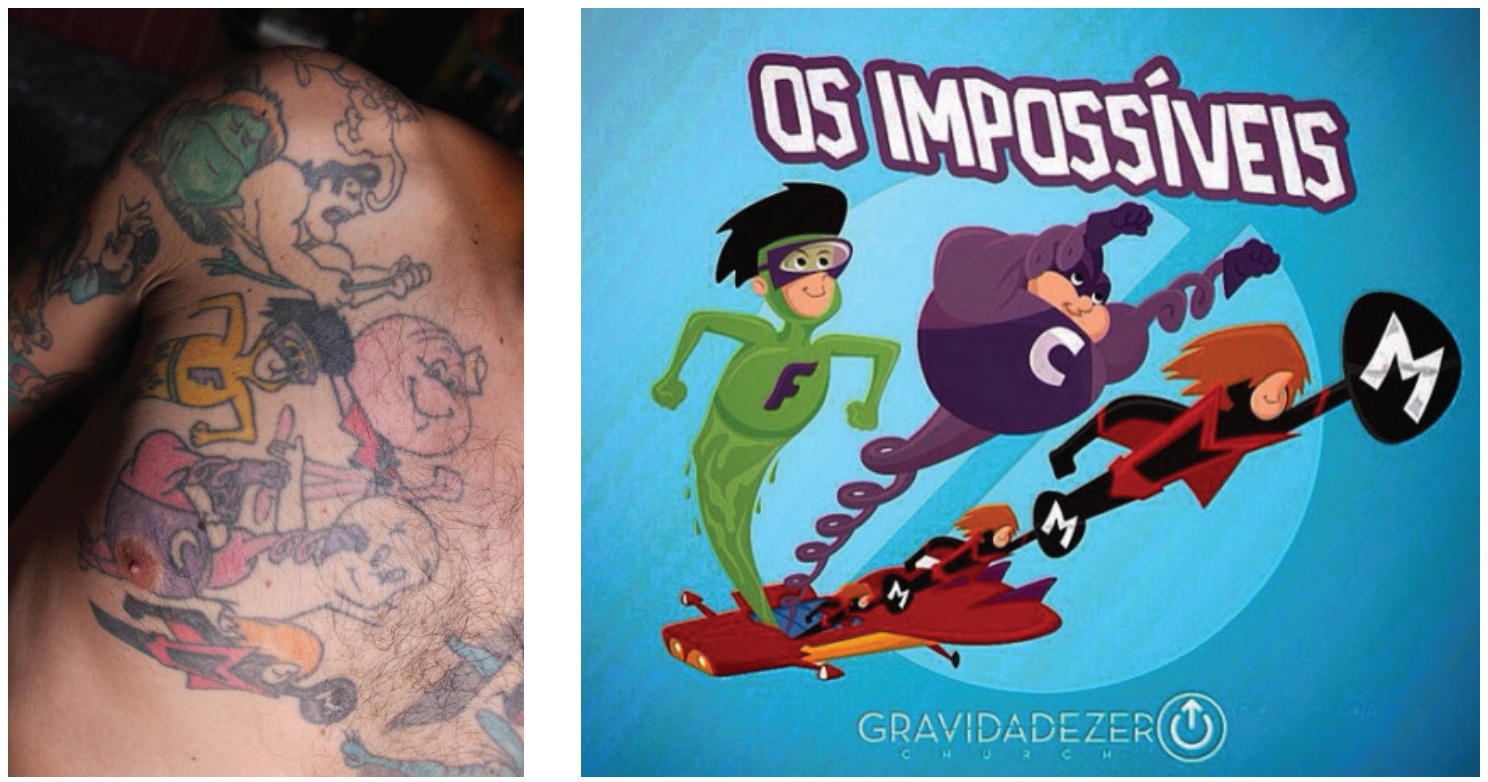

Fontes: (A) do autor, 2015; (B) site Gravidade Zero

Essas tatuagens, por exemplo, apresentam-se, predominantemente, como um legissigno indicial, um signo convencional que se refere a um objeto concreto, localizado em um tempo e espaço. De acordo com Peirce (2003, p. 56), o legissigno indicial é um tipo de lei, norma ou convenção "que requer que cada um de seus casos seja realmente afetado por seu Objeto de tal modo que simplesmente atraia a atenção para esse objeto", no caso de um interpretante remático, e "forneça uma informação definida a respeito desse 0bjeto", no caso de um interpretante dicente. Entretanto, como todo índice contém em si um ícone, é natural que exerça também a função de um legissigno icônico: "todo tipo, ou lei geral, na medida em que exige que cada um de seus casos corporifique uma qualidade definida que o torna adequado para trazer à mente a ideia de um objeto semelhante" (PEIRCE, 2003, p. 55).

Ou seja, o reconhecimento da figura se dá pela semelhança entre as formas, traços e cores da tatuagem com as formas, traços e cores da imagem veiculada nas mídias impressa e televisiva. Semelhança essa que é resultado da reprodução de modelos determinados. No processo de interpretação, a semelhança da tatuagem com a imagem de divulgação permite ao observador, se este teve experiência colateral com o objeto, reconhecer os personagens e suas relações na narrativa.

A grande maioria das tatuagens de PA apresentase sob essa lógica. No entanto, ao falar sobre os 
procedimentos de escolha das imagens a serem tatuadas, PA aparenta não ter conhecimento nem preocupação com essas normas: "Eu valorizava muito aquilo que eu encontrava. [...] eram recortes de revista e tudo mais. Então, o que eu achava... eu gostava... eu colocava”. Ou seja, os padrões eram seguidos apenas porque as imagens eram facilmente encontradas.

Assim como as tatuagens de PA, certas figuras no corpo de PB também são réplicas de imagens já veiculadas em outras mídias. A figura do personagem Flash, tatuada em seu braço direito, é uma reprodução do personagem lançado na série Os Novos 52 (Figura 3). Ao seguir modelos determinados, domínio do legissigno, as reproduções se materializam em signos particulares, réplicas de originais, sinsignos. Porém, tal signo só pode indicar uma existência por evidenciar o caráter icônico da imagem, a semelhança do desenho da tatuagem com imagens veiculadas em revistas, na internet, etc., aspecto qualitativo do signo. Essa relação revela que o reconhecimento da figura tatuada, a qual aparenta ser importante para a pessoa tatuada, está diretamente relacionado à adoção de modelos determinados pelas empresas detentoras do direito de imagem dos personagens. Mesma lógica do negócio de licenciamento.

0 signo icônico, que Peirce divide em três (imagem, diagrama e metáfora), só pode sugerir, por meio da semelhança, um dado objeto. A relação de semelhança que a imagem estabelece com o objeto dinâmico está no nível da aparência, a relação que o diagrama estabelece está nas relações internas e a metáfora, na similaridade com o significado.

Figura 3: Imagem do personagem Flash: (A) como tatuagem no braço de PB; (B) em ilustração de divulgação do personagem na série Os Novos 52.
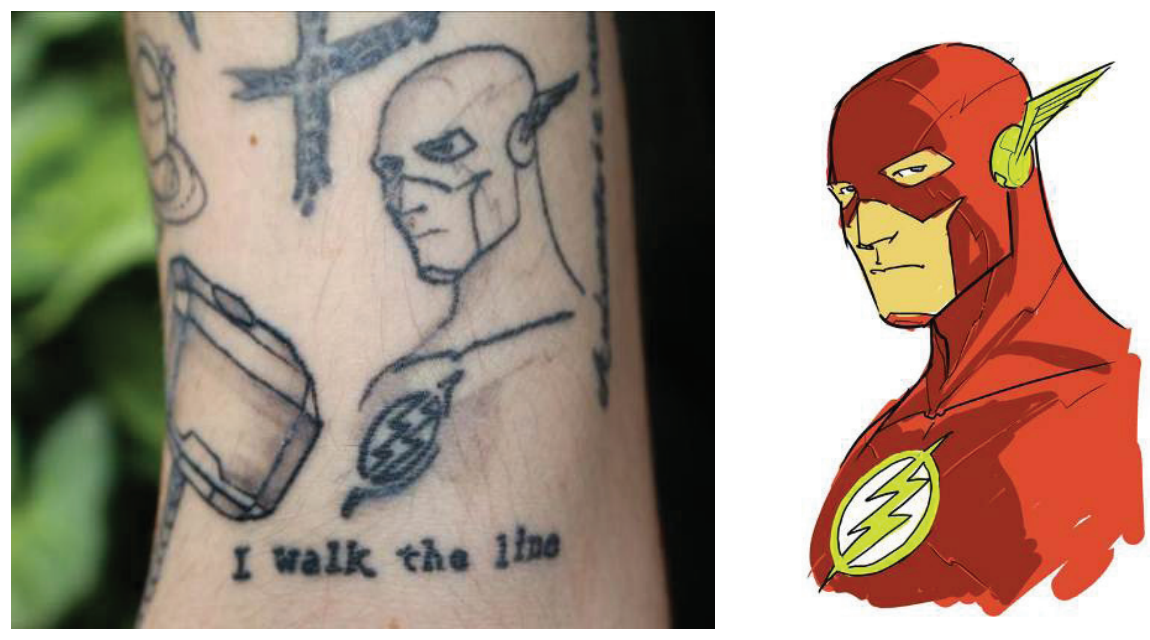

Fontes: (A) do autor, 2015; (B) site MTV. 
As relações de semelhança por aparência

(imagem) são observadas tanto nas tatuagens de PA quanto de PB. Isso se deve ao interesse dos dois em exibir imagens que sejam reconhecidas pelos observadores.

Apenas uma figura na pele de PB não é cópia de uma imagem já veiculada na mídia e exige uma atenção maior do observador. A figura do Superman (Figura 4), que se esconde em sua costela, foi feita com uma técnica reconhecida como watercolour, em que as cores não são delimitadas por traços precisos. A plasticidade dessa figura faz com que ela permaneça em baixa pregnância, e os aspectos qualitativos sejam proeminentes. Essa figura, como outras duas que são relacionadas a inscrições apresentamse como metáforas. Os significados internos das figuras, que se desenvolveram nas narrativas, são associados à vida do portador: "Superman simboliza muita coisa na minha vida, [...] mostrar que eu também fui de aço algumas vezes" (PB).

Além de optar por estilos estéticos predominantes no mercado de tatuagem, os quais diferem dos padrões de reprodução dos personagens, PB afirma seguir uma tendência contemporânea de projeto de corpo tatuado: pequenas tatuagens, com tratamentos e temáticas distintas, cobrindo todo o braço. É possível observar no corpo dele detalhes ou símbolos conhecidos apenas pelos fãs, como os símbolos dos personagens Batman e

Figura 4: Figura aquarelada de Superman na costela direita.

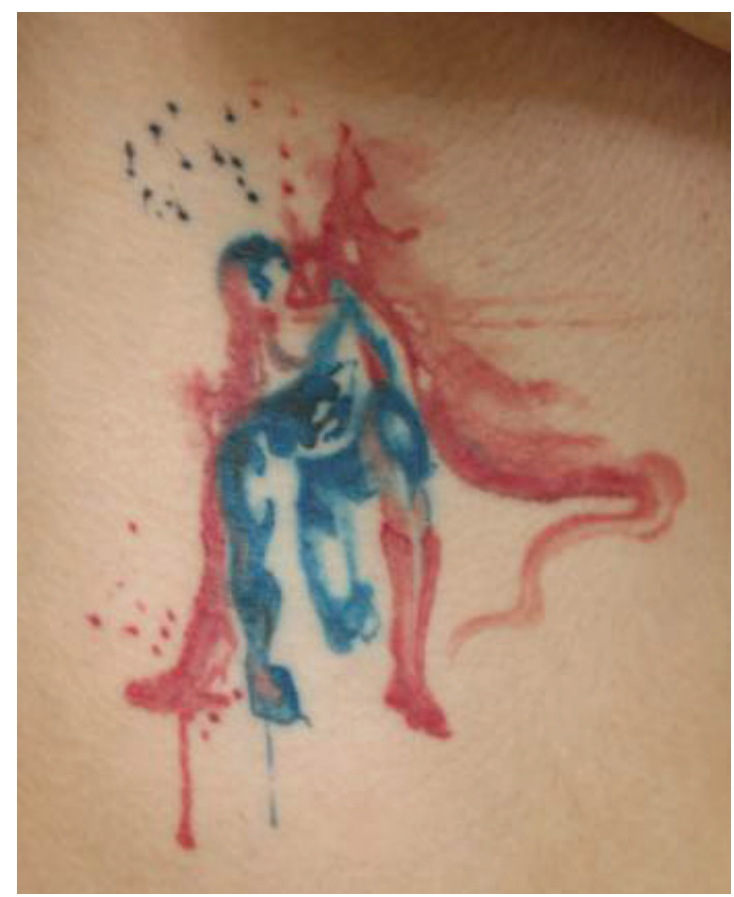

Fonte: do autor, 2015. 
Nigthtwin e o elmo do personagem Magneto (da série $X$ Man), que só permitem o reconhecimento imediato de outros aficionados pelas séries
(Figura 5). Alguns desses símbolos são combinados com inscrições em inglês - 0 título de uma música e o nome de uma banda inglesa.

Figura 5: À esquerda: imagem do símbolo de Batman; à direita: imagem do elmo do personagem e inscrição abaixo
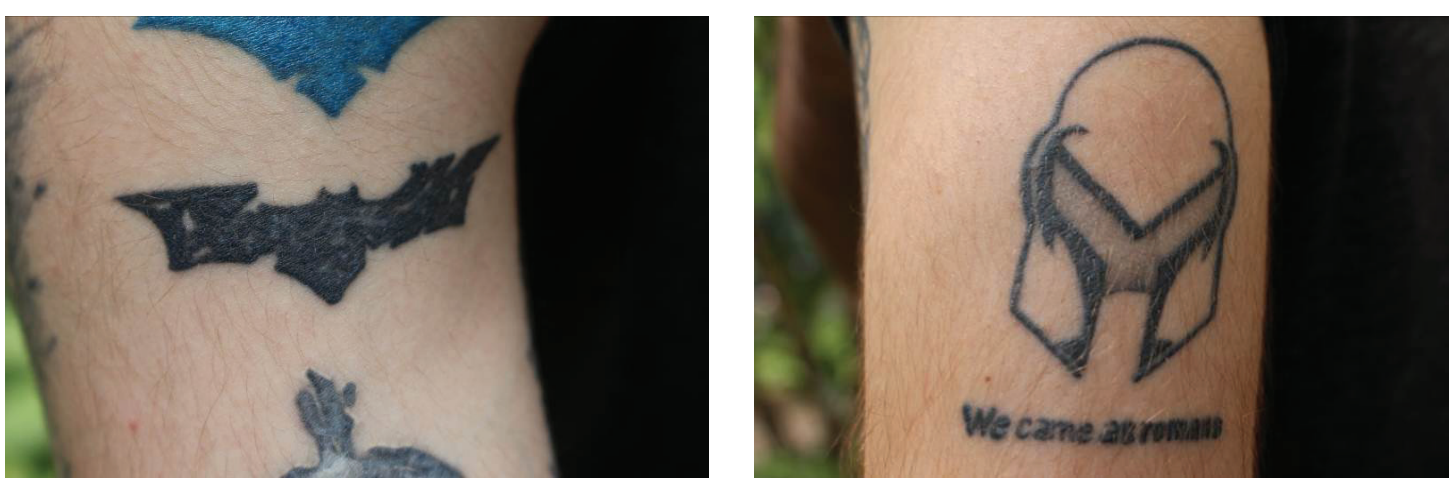

Fonte: do autor, 2015.

As relações estabelecidas entre as figuras

e as inscrições, hábito comum na tatuagem contemporânea, visam dotar a imagem de um novo sentido - domínio do legissigno simbólico, signo este que parte de uma convenção e é interpretado sob a forma de um enunciado.

Nesse caso, é necessário que o intérprete tenha conhecimento dessas regras. Mas, como muitas dessas regras são definidas pelo próprio portador, é por meio de seu discurso que o intérprete estabelece as relações. PB justifica sua tatuagem afirmando o seguinte: "0 elmo do Magneto remete a um capacete meio romano e eu achei que essa... o nome dessa banda [We came as romans] combinaria um pouco com 0 capacete do
Magneto". PB também atribui à imagem do elmo do personagem Magneto certos sentidos que não estão relacionados ao nome da banda inglesa. Para ele, 0 desenho representa a luta por causas que refletem "o que acontece na sociedade", significado esse que, embora exista na história do personagem, só faz sentido em sua tatuagem por meio de seu discurso: "Magneto defende uma causa de mutantes, de uma adaptação dos seres humanos" (PB).

Ao contrário de PA, que sobrepõe as normas da indústria dos quadrinhos aos hábitos relacionados com a prática de se tatuar, PB demonstra dar mais valor às práticas de se tatuar do que às regras de reprodução das figuras. 


\section{A singularidade no desenho e no corpo}

Existem práticas comuns na ilustração para histórias em quadrinhos e práticas próprias do desenho de tatuagem (dimensão do legissigno) que determinam certas qualidades às representações.

As histórias em quadrinhos podem ser categorizadas a partir do estilo, tipo de traço ou tratamento estético (CARDOSO; SANTOS, 2015). Ao optar por um determinado estilo (realista ou cartunesco), por um tipo de traço (linha fina em oposição à linha grossa) e por um tratamento estético (limpo em oposição a sujo), o desenhista acaba optando por utilizar técnicas e materiais que permitem alcançar o resultado desejado - o qual pode ir dos tradicionais lápis e tintas até recursos digitais, passando por colagens e materiais alternativos. 0 tipo de traço e 0 tratamento estético estão aptos a destacar qualidades estéticas na ilustração. 0u seja, essas técnicas, como normas gerais (domínio do legissigno), são aplicadas em situações particulares (domínio do sinsigno) visando dotar o desenho de certas qualidades (domínio do qualissigno). Da mesma maneira, as questões técnicas também precisam ser consideradas no momento de definir o desenho para uma tatuagem.

No desenho de tatuagem, 0 tratamento que predomina atualmente é 0 estético limpo, ou seja, as linhas finas privilegiam a clareza e legibilidade da figura. Ainda que existam sombras, principalmente nas tatuagens em preto e branco, elas normalmente são suaves. Nesse sentido, 0 tipo de linha da tatuagem não é necessariamente o tipo de linha do desenho original. A preocupação com 0 resultado da tatuagem (qualidades estéticas dos desenhos) se sobrepõe à intenção de representar com maior fidelidade 0 original. Nesse caso, as técnicas que predominam na prática de tatuar se impõem às normas de produção do mercado de quadrinhos.

0 processo de escolha da figura, do tratamento estético e do local do corpo é parte de um projeto que envolve tanto técnicas conhecidas pelo tatuador como interesses particulares do indivíduo que será tatuado. Nesse sentido, é preciso considerar a singularidade das figuras, do conjunto e do contexto. É necessário discriminar os limites das características existenciais, aquilo que é único, domínio do sinsigno.

A tatuagem, nessa etapa da análise, deve ser vista como algo que existe em um tempo e espaço determinados, parafraseando Santaella (2002, p. 71): "de acordo com as funções que desempenha, as finalidades a que se presta". Logo, o exame considera as formas como essas figuras foram apropriadas e as finalidades de cada uma. Os modelos selecionados estabelecem uma conexão existencial com uma produção cultural específica. É nessa direção que o objeto imediato de um índice indica seu objeto dinâmico. Conforme Santaella, "para agir indicialmente, o signo deve ser considerado no seu aspecto existencial como 
parte de um outro existente para 0 qual 0 índice aponta e de que 0 índice é uma parte" (2002, p. 20). Desse modo, cada tatuagem de PA e PB aponta para uma ilustração, a qual possui uma narrativa, com personagens que apresentam certas qualidades.

Ainda que no corpo de PA os personagens se materializem a partir de modelos já exibidos em outras mídias, e sigam certas normas de reprodução das empresas detentoras do direito de imagem, a organização dessas figuras apresenta-se como uma composição particular, única. Essa composição é determinada por interesses próprios. Segundo o comerciante, seu principal objetivo é reunir o maior número possível de personagens em seu corpo, por isso, ao invés de tatuar as figuras dos personagens por inteiro, como fazia antes, ele opta por desenhar apenas parte da figura: "para caber no resto [do corpo] o que ainda falta, eu tenho que optar por cabecinhas".

0s mais de 120 personagens impressos na pele de PA estão organizados em grupos por toda a parte superior do corpo: nos ombros, no peito, nas costas, nos braços. Esses grupos apresentam personagens de uma mesma animação ao lado de personagens de outras produções. Ao redor do braço direito (Figura 6), por exemplo, exibem-se quase 20 personagens de diferentes empresas, como, por exemplo: Mickey, as duplas Tom e Jerry e Coiote e Papa-Léguas, o Sargento Tainha, da série Recruta Zero, entre outros.
Figura 6: Detalhe do corpo de PA

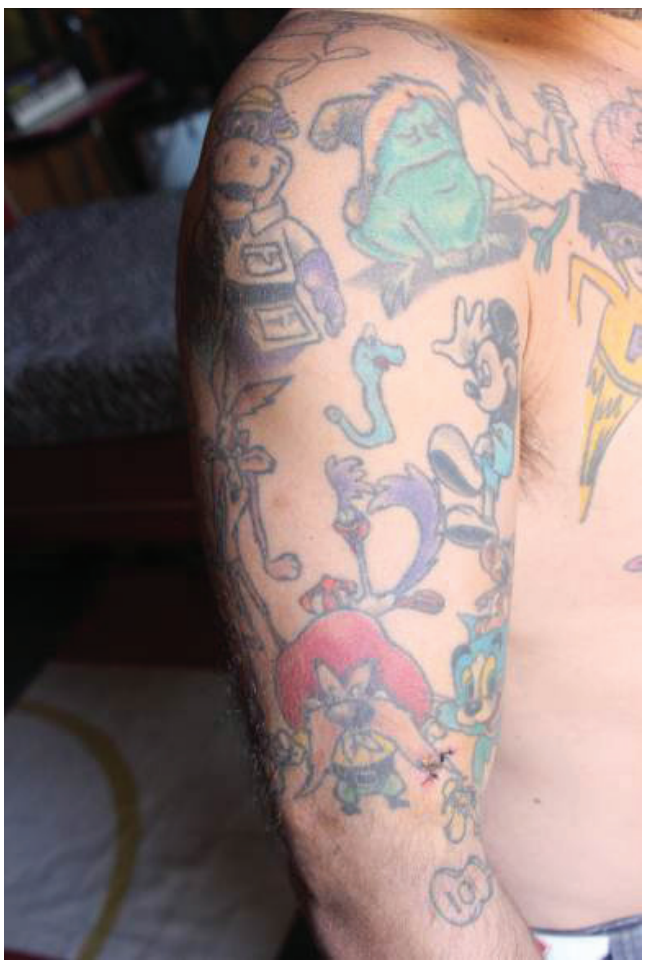

Fonte: do autor, 2015.

Diferentemente de PA, que só possui tatuagens de personagens, $\mathrm{PB}$ combina os comics com ilustrações de outros tipos (Figura 7). No que se refere especificamente às tatuagens de personagens, são todas de super-heróis, da Marvel Comics e da DC Comics. No braço direito de PB, estão tatuadas aproximadamente 15 figuras e quatro inscrições. As figuras dos personagens apresentam-se da seguinte forma: imagens do tipo retrato (busto ou rosto), imagens dos personagens fazendo poses, símbolos e artefatos. Das figuras, nove são referências a super-heróis, sendo que duas dessas estabelecem relações com frases. PB também combina tatuagens de diferentes 
estilos, como, por exemplo, blackwork,

watercolour e traditional. Apenas o símbolo dos personagens Nightwin e a máscara do HomemAranha são coloridos (Figura 7). No outro braço aparecem duas figuras: 0 elmo do personagem Magneto, da série X-Man, e uma inscrição sob esta figura, o nome de uma banda inglesa (Figura 5). Na costela, com um tratamento estético diferenciado, aquarelado (watercolour), uma única imagem de um super-herói.

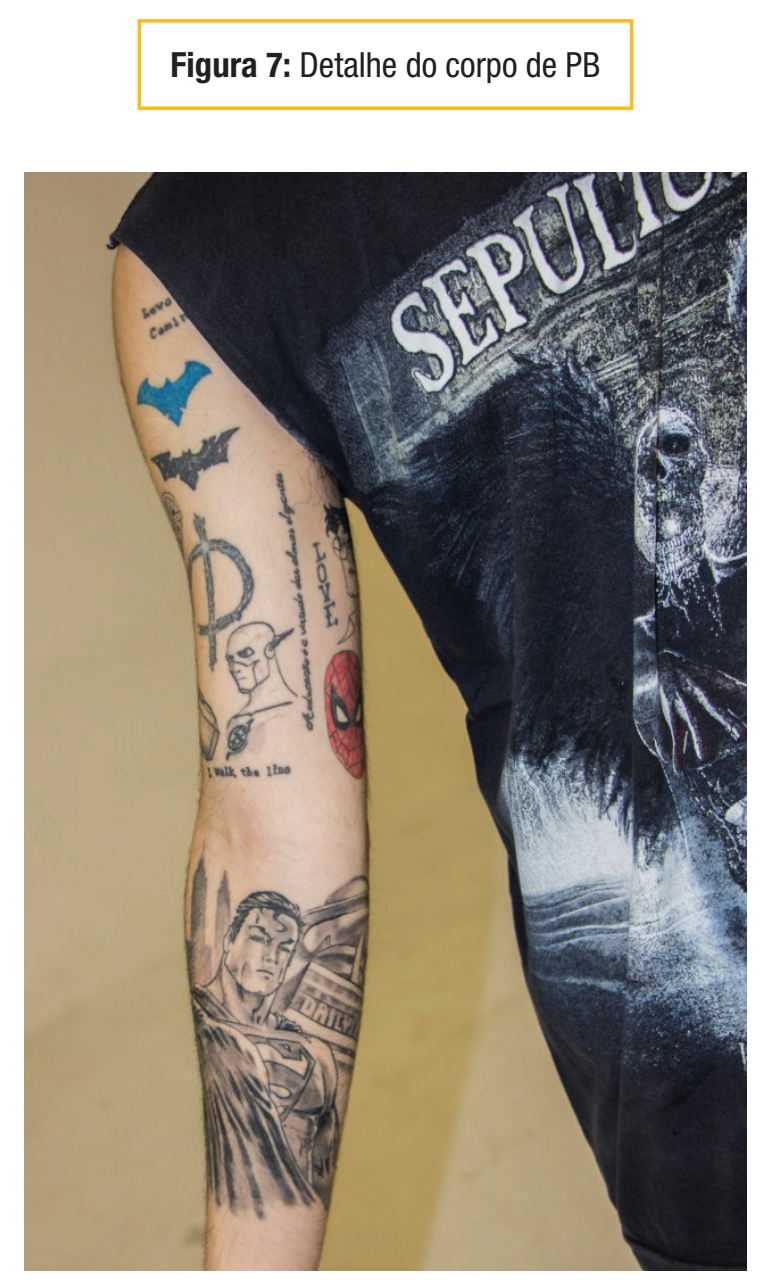

Fonte: do autor, 2015.

\section{A metáfora do álbum}

Ainda que compartilhem o mesmo interesse por essa temática e aparentem certo comportamento comum no que diz respeito ao consumo desse tipo de produto, ao tirar as imagens de seus contextos e atribuir a elas um novo sentido, PA e PB apresentam duas propostas distintas de uso das personagens como tatuagens. 0 primeiro visa facilitar o reconhecimento das figuras; 0 outro exige 0 conhecimento de elementos da narrativa e 0 estabelecimento de relação com elementos de outros sistemas.

PA assume estar mais preocupado com o conjunto. Ao afirmar "eu me considero um álbum", 0 comerciante revela que pretende tatuar o maior número de figuras possível, como um álbum de figurinhas colecionável. Fazendo isso, entende que conseguirá resgatar parte de sua infância e transmitir às crianças valores que considera positivos. PB, por outro lado, aparenta seguir a lógica do álbum de família. Prefere preservar apenas algumas lembranças do passado e registrar eventos do presente com vistas à manutenção da memória futura.

Eu gosto de escolher minuciosamente as tatuagens. Tipo, uma por uma pra definir determinadas fases da minha vida, o que representa cada uma, porque eu me lembro do que se passava na minha vida; [...] quando o braço estiver fechado, haverá várias tatuagens em todos os lugares, cada uma representará uma coisa [...], porque cada uma representa uma fase da minha vida e é isso que eu acho mais interessante em tatuagem. (PB) 
Se para PA o conjunto de figuras representa a época de sua infância, para PB cada imagem isolada representa um momento específico de sua vida. Ao converterem seus corpos em mídia - em um meio destinado ao registro, à preservação e à comunicação de suas memórias -, cada um à sua maneira, geram um novo sentido a esse tipo de signo midiático. 0 primeiro, utilizando a metáfora do álbum de coleção, próprio para a colagem de selos ou figurinhas, desvela outra metáfora, a do álbum de recordação, próprio para colagem de retratos, anotações e registros de eventos vividos. Se a este último interessa o registro em si, que permite narrar uma história em um tempo e espaço precisos, ao outro interessa acumular o maior número possível de imagens. Se para PB a história e personalidade do personagem são importantes para expressar o que ele deseja dizer, para PA o mais importante é manter o rigor na escolha de personagens de um tipo específico, os que aparecem nos desenhos animados veiculados na televisão brasileira nas décadas de 1970 e 1980, os quais remetem diretamente à sua infância.

Se para 0 estudante português os espaços selecionados para as tatuagens fazem parte de um planejamento de corpo que envolve também tatuagens de outros tipos, para o comerciante brasileiro a escolha dos espaços se dá em razão do melhor aproveitamento que possibilita inserir a maior quantidade possível de personagens.

Entretanto, percebe-se que a metáfora dos álbuns, ainda que sirva para se referir a objetos distintos, revela um comportamento comum. Tanto
0 álbum de coleção como o de memórias falam mais para a própria pessoa que 0 coleciona do que para os outros. De modo geral, um álbum não é feito com o principal objetivo de ser mostrado para outros. Ao contrário disso, ele serve para preservar a memória e manter um pouco do que se pensa ser. Quando é exibido para outro, serve para relembrar um passado e/ou reafirmar uma identidade. Ou seja, o mais importante é que essas imagens permaneçam guardadas para serem visitadas quando se deseja. Mais do que uma tendência motivada por um comportamento coletivo, a tatuagem de personagem traz em si parte da história de seu portador: "Não era uma questão de moda, eu queria fazer alguma coisa que me lembrasse... que me fizesse feliz. [...] Quando eu tatuava e me olhava no espelho, parecia que eu tinha completado algo na minha vida" (PA). De maneira geral, todo álbum exerce a função de objeto biográfico, objetos que, de acordo com Bosi (2003, p. 25-26), "nos dão um assentimento à nossa posição no mundo, à nossa identidade", representam "experiência vivida, uma aventura afetiva". Para ela, a permanência dessas referências nos dá a sensação de continuidade, a ideia de que nos mantemos como sempre fomos ou a persistente lembrança do que fomos e não gostaríamos de esquecer.

\section{Considerações finais}

Como se observou, os portadores de comics tattoos fazem uso desse tipo de signo para narrar suas próprias histórias e construir 
suas identidades. Para isso, seguem certas convenções e técnicas na reprodução de personagens licenciados e práticas de tatuagem, como, por exemplo: manutenção de invariantes imagéticas, tipos de linhas, estilos e tratamento estético; adoção de padrões recorrentes de uso de personagens fora do contexto da narrativa; estabelecimento de relações simbólicas relacionadas à tatuagem e ao personagem. Essas imagens, por sua vez, geram novos sentidos por meio de seus discursos, das histórias que contam, ou seja, certos "acordos" são feitos para que, em determinados momentos, sejam adotadas normas de um sistema e, em outros momentos, de outro, tendo em vista o objetivo maior que é dizer um pouco sobre si mesmo e fazer com que 0 observador reconheça a figura.

Contudo, nota-se que o discurso do portador nem sempre está ajustado ao potencial de significação dessas imagens. Alguns sentidos intrínsecos aos personagens, que se desenvolvem nas narrativas, são relacionados com acontecimentos vividos, crenças e valores. Outros não. São criados nas relações estabelecidas entre as imagens e os textos verbais ou no uso da imagem como metáfora para um acontecimento.

São esses laços que permitem ao personagem narrar uma história sobre seu portador, mesmo quando essas histórias não são completamente verdadeiras. São esses laços que propiciam ao portador explicar ou justificar a figura tatuada, mesmo quando parte de sua própria história é recriada. A tessitura das narrativas entrelaça elementos de vivência com elementos do imaginário. Ao mesmo tempo em que colabora para 0 desenvolvimento de uma identidade, revela como o portador entende a si e ao mundo.

\section{Referências}

BOSI, E. 0 tempo vivo da memória - ensaios de Psicologia Social. São Paulo: Ateliê Editorial, 2003.

CARDOSO, J. B. F. No muro, na roupa, na pele: o personagem na paisagem urbana. In: Revista Comunicação \& Inovação. São Caetano do Sul: USCS, p. 73-91, 2016. Disponível em: http://seer.uscs.edu. br/index.php/revista_comunicacao_inovacao/article/ view/3915. Acesso em: 09/05/2017.

CARDOSO, J. B. F; SANTOS, R. E. There's life in other systems: the comic character outside narratives. In: International Journal of Comic Art. Philadelphia: Temple University, v.17, p. 547 - 560, 2015.

FALKENSTERN, R. C. Illusion of permanence: tattoos and the temporary self. In: ARP, R. (ed.). Tattoos philosophy for everyone: I ink, therefore I am. Oxford: Wiley-Blackwell, p. 96-108. 2012.

FRUH, K; THOMAS, E. Tattoo you: personal identity in ink. In: ARP, R. (ed.). Tattoos - philosophy for everyone: I ink, therefore I am. Oxford: Wiley-Blackwell, p. 83-95, 2012.

GORDON, I. Comic Strips and Consumer Culture - 1890-1945. Washington: Smithsonian Institution Press, 1998.

LEE, W. L. Never merely "there": tattooing as a practice of writing and telling stories. In: ARP, R. (ed.). Tattoos - philosophy for everyone: I ink, therefore I am. Oxford: Wiley-Blackwell, p. 151-164. 2012.

OSÓRIO, A. B. 0 gênero da tatuagem: Continuidades e novos usos relativos à prática na cidade do Rio 
de Janeiro. 2006. 258p. Tese de doutorado - IFCS, Doutorado em Antropologia, PPGSA, UFRJ. Rio de Janeiro: 2006.

PAVAN, M. A; SILVA, J. C. Tatuagem: cultura de massas e afirmação subjetiva incorporadas. Revista Signos do Consumo. São Paulo: USP, v. 2, p. 1-16, 2010.

PEIRCE, C. S. Semiótica. São Paulo: Perspectiva, 2003. PEREZ FONSECA, A. L. Cuerpos tatuados, "almas" tatuadas: nuevas formas de subjetividad en la contemporaneidad. Revista Colombiana de Antropología. Bogotá: ICANH. v. 45, jan./jun. p. 6984,2009 .

PUSTZ, M. J. Comic Book Culture: fanboys and true believers. Jackson: University Press of Mississippi, 1999.

SANTAELLA, L. Semiótica Aplicada. São Paulo:

Thonsom, 2002.

SMITH, C. My tattoo may be permanent, but my memory of it isn't. In: ARP, R. (ed.) Tattoos philosophy for everyone: I ink, therefore I am. 0xford: Wiley-Blackwell, p. 109-120, 2012.

TALIAFERRO, C; ODDEN, M. Tattoos and the tattooing arts in perspective: An overview and some preliminary observations. In: ARP, R. (ed.). Tattoos - philosophy for everyone: I ink, therefore I am. 0xford: WileyBlackwell, p. 3-13, 2012. 


\begin{tabular}{|c|c|}
\hline $\begin{array}{l}\text { Comics Tattoos: } \\
\text { rules and singularity }\end{array}$ & $\begin{array}{l}\text { Comics Tattoos: } \\
\text { normas y singularidades }\end{array}$ \\
\hline $\begin{array}{l}\text { Abstract } \\
\text { The present text aims to characterize the different } \\
\text { types of use Comics Tattoos and verify the potential of } \\
\text { significance. To achieve these objectives, the research } \\
\text { used techniques such as in-depth interviews and } \\
\text { documentary analysis, on the basis of the Peircean } \\
\text { semiotics. The interviews and analysis confirmed that } \\
\text { are various ways to use character as tattoo, which } \\
\text { are defined by reason of the history that want to } \\
\text { say. While appropriating of the communication and } \\
\text { entertainment industry's images, the tattoo artist and } \\
\text { the tattooed person establish agreements between the } \\
\text { rules that guide the appropriation and reproduction } \\
\text { of the comics' characters' images and the conventions } \\
\text { and habits connected with the tattoo usage and the } \\
\text { tattooing practice. } \\
\text { Keywords } \\
\text { Character. Comics Tattoo. Comics. } \\
\text { Peircean Semiotics. }\end{array}$ & $\begin{array}{l}\text { Resumen } \\
\text { El texto objetiva caracterizar diferentes tipos de } \\
\text { usos de Comics Tattoos y verificar su potencial } \\
\text { de significación. Para alcanzar los objetivos se } \\
\text { realizaran entrevistas en profundidad y análisis } \\
\text { documental, basada en la semiótica de Peirce. Las } \\
\text { entrevistas y análisis permitieron constatar que } \\
\text { existen diferentes formas de uso de personajes como } \\
\text { tatuajes, que son definidas en razón de la historia } \\
\text { que se desea contar. Al apropiarse de imágenes de } \\
\text { la industria de comunicación y entretenimiento, el } \\
\text { artista del tatuaje y el sujeto tatuado establecen } \\
\text { "acuerdos" entre las normas que orientan la } \\
\text { apropiación y reproducción de imágenes de } \\
\text { personajes y las convenciones y hábitos relacionados } \\
\text { al uso y práctica de tatuarse. } \\
\text { Palabras clave } \\
\text { Personaje. Comics Tattoo. Comics. } \\
\text { Semiótica Peirceana. }\end{array}$ \\
\hline
\end{tabular}




\section{Expediente}

A revista E-Compós é a publicação científica em formato eletrônico da Associação Nacional dos Programas de Pós-Graduação em Comunicação (Compós). Lançada em 2004, tem como principal finalidade difundir a produção acadêmica de pesquisadores da área de Comunicação, inseridos em instituições do Brasil e do exterior.

\section{E-COMPÓS I www.e-compos.org.br I E-ISSN 1808-2599}

Revista da Associação Nacional dos Programas de Pós-Graduação em Comunicação.

Brasília, v.20, n.1, jan./abr. 2017.

A identificação das edições, a partir de 2008, passa a ser volume anual com três números.

Indexada por Latindex I www.latindex.unam.mx

\section{CONSELHO EDITORIAL}

Alda Cristina Silva da Costa, Universidade Federal do Pará, Brasil Alfredo Luiz Paes de Oliveira Suppia, Universidade Estadual de Campinas, Brasil Álvaro Larangeira, Universidade Tuiuti do Paraná, Brasil Ana Carolina D. Escosteguy, Pontifícia Universidade Católica do Rio Grande do Sul, Brasil Ana Regina Barros Rego Leal, Universidade Federal do Piauí, Brasil Ana Carolina Rocha Pessôa Temer, Universidade Federal de Goiás, Brasil Andrea França, Pontifícia Universidade Católica do Rio de Janeiro, Brasil André Luiz Martins Lemos, Universidade Federal da Bahia, Brasil Angela Cristina Salgueiro Marques, Faculdade Cásper Libero, Brasil Ângela Freire Prysthon, Universidade Federal de Pernambuco, Brasil Antonio Carlos Hohlfeldt, Pontifícia Universidade Católica do Rio Grande do Sul, Brasil Arthur Ituassu, Pontifícia Universidade Católica do Rio de Janeiro, Brasil Bruno Campanella, Universidade Federal Fluminense, Brasil Cláudio Novaes Pinto Coelho, Faculdade Cásper Líbero, Brasil Carlos Eduardo Franciscato, Universidade Federal de Sergipe, Brasil Denise Tavares da Silva, Universidade Federal Fluminense, Brasil Eduardo Vicente, Universidade de São Paulo, Brasil Eliza Bachega Casadei, Escola Superior de Propaganda e Marketing - SP, Brasil Elizabeth Nicolau Saad Corrêa, Universidade de São Paulo, Brasil Erick Felinto de Oliveira, Universidade do Estado do Rio de Janeiro, Brasil Erly Vieira Júnior, Universidade Federal do Espirito Santo, Brasil Francisco de Assis, FIAM-FAAM Centro Universitário, Brasil Francisco Elinaldo Teixeira, Universidade Estadual de Campinas, Brasil Frederico de Mello Brandão Tavares, Universidade Federal de Ouro Preto, Brasil Gabriela Reinaldo, Universidade Federal do Ceará, Brasil Gilson Vieira Monteiro, Universidade Federal do Amazonas, Brasil Gustavo Daudt Fischer, Universidade do Vale do Rio dos Sinos, Brasil Igor Sacramento, Fundação Oswaldo Cruz, Brasil Itania Maria Mota Gomes, Universidade Federal da Bahia, Brasil Jiani Adriana Bonin, Universidade do Vale do Rio dos Sinos, Brasil José Afonso da Silva Junior, Universidade Federal de Pernambuco, Brasil
José Luiz Aidar Prado, Pontifícia Universidade Católica de São Paulo, Brasil Juçara Gorski Brittes, Universidade Federal de Ouro Preto, Brasil Laura Loguercio Cánepa, Universidade Anhembi Morumbi, Brasil Liziane Soares Guazina, Universidade de Brasilia, Brasil Luíza Mônica Assis da Silva, Universidade Católica de Brasília, Brasil Maria Ataide Malcher, Universidade Federal do Pará, Brasil Maria Elisabete Antonioli, Escola Superior de Propaganda e Marketing - SP, Brasil Maria das Graças Pinto Coelho, Universidade Federal do Rio Grande do Norte, Brasil Marcel Vieira Barreto Silva, Universidade Federal da Paraíba, Brasil Marcia Tondato, Escola Superior de Propaganda e Marketing, Brasil Marli Santos, Universidade Metodista de São Paulo, Brasil Márcio Souza Gonçalves, Universidade do Estado do Rio de Janeiro, Brasil Mauricio Mario Monteiro, Universidade Anhembi Morumbi, Brasil Mauricio Ribeiro da Silva, Universidade Paulista, Brasil Mauro de Souza Ventura, Universidade Estadual Paulista, Brasil Mayka Castellano, Universidade Federal Fluminense, Brasil Micael Maiolino Herschmann, Universidade Federal do Rio de Janeiro, Brasil Mozahir Salomão Bruck, Pontifícia Universidade Católica de Minas Gerais, Brasil Nísia Martins Rosario, Universidade Federal do Rio Grande do Sul, Brasil Potiguara Mendes Silveira Jr, Universidade Federal de Juiz de Fora, Brasil Raquel Ritter Longhi, Universidade Federal de Santa Catarina, Brasil Regiane Regina Ribeiro, Universidade Federal do Paraná, Brasil Roberto Elísio dos Santos, Universidade Municipal de São Caetano do Sul, Brasil Rodolfo Rorato Londero, Universidade Estadual de Londrina, Brasil Sérgio Luiz Gadini, Universidade Estadual de Ponta Grossa, Brasil Simone Maria Andrade Pereira de Sá, Universidade Federal Fluminense, Brasil Simone Maria Rocha, Universidade Federal de Minas Gerais, Brasil Suzana Reck Miranda, Universidade Federal de São Carlos, Brasil Tarcyanie Cajueiro Santos, Universidade de Sorocaba, Brasil Tatiana Oliveira Siciliano, Pontifícia Universidade Católica do Rio de Janeiro, Brasil Veneza Mayora Ronsini, Universidade Federal de Santa Maria, Brasil

\section{CONSELHO CIENTÍFICO}

Cristiane Freitas Gutfreind, Pontifícia Universidade Católica do Rio Grande do Sul, Brasil Eduardo Morettin, Universidade de São Paulo, Brasil

Felipe Costa Trotta, Universidade Federal Fluminense, Brasil Irene de Araújo Machado, Universidade de São Paulo, Brasil

\section{COMISSÃO EDITORIAL}

Eduardo Antonio de Jesus, Universidade Federal de Minas Gerais, Brasil Marco Antonio Roxo da Silva, Universidade Federal Fluminense, Brasil Osmar Gonçalves dos Reis Filho, Universidade Federal do Ceará, Brasil

\section{CONSULTORES AD HOC}

Kelly C. de Souza Prudencio, Universidade Federal do Paraná, Brasil Francisco P. Jamil A. Marques, Universidade Federal do Paraná, Brasil Tiago Quiroga F. Neto, Universidade de Brasília, Brasil

\section{EQUIPE TÉCNICA}

ASSISTENTE EDITORIAL Márcio Zanetti Negrini REVISÃO DE TEXTOS Press Revisão EDITORAÇÃO ELETRÔNICA Roka Estúdio IMAGEM DE CAPA Silas de Paula

\section{COMPÓS I www.compos.org.br}

Associação Nacional dos Programas de Pós-Graduação em Comunicação

Presidente

Edson Fernando Dalmonte

Programa de Pós-Graduação em Comunicação

e Cultura Contemporânea - UFBA

edsondalmonte@uol.com.br

Vice-presidente

Cristiane Freitas Gutfreind

Programa de Pós-Graduação em Comunicação Social - PUC-RS cristianefreitas@pucrs.br

Secretário-Geral

Rogério Ferraraz

Programa de Pós-Graduação em Comunicação

Universidade Anhembi Morumbi

rogerioferraraz@anhembimorumbi.edu.br

CONTATO I revistaecompos@gmail.com 